\title{
O ensino de bioquímica da respiração celular facilitado por aplicativo para aparelho
}

\section{celular}

\author{
The teaching of cell respiration biochemistry facilitated by a mobile device application \\ La enseñanza de la bioquímica de la respiración celular facilitada por la aplicación móvil
}

Recebido: 31/01/2022 | Revisado: 05/02/2022 | Aceito: 13/02/2022 | Publicado: 18/02/2022

\author{
Antonio Delmário Alves dos Santos \\ ORCID: https://orcid.org/0000-0001-9437-2857 \\ Universidade do Estado do Rio Grande do Norte, Brasil \\ E-mail: delmariodavi@gmail.com \\ Pablo de Castro Santos \\ ORCID: https://orcid.org/0000-0003-0081-9609 \\ Universidade do Estado do Rio Grande do Norte, Brasil \\ E-mail: pablocastro@uern.br \\ Regina Célia Pereira Marques \\ ORCID: https://orcid.org/0000-0002-5172-0441 \\ Universidade do Estado do Rio Grande do Norte, Brasil \\ E-mail: marques.regina@gmail.com
}

\begin{abstract}
Resumo
As Tecnologias da Informação e da Comunicação - TICs, trazem novas possibilidades para o ensino e para a aprendizagem de temas próprios da Bioquímica. O ensino híbrido e as metodologias ativas, associados as ferramentas tecnológicas educacionais, podem determinar a quebra de paradigmas no âmbito do fazer pedagógico. Para analisar as relações entre ensino híbrido e a metodologia ativa sala de aula invertida, este trabalho utilizou o aplicativo Bio Respiração, uma ferramenta de ensino para facilitar o ensino da respiração celular. A utilização de questionários específicos sobre o ensino da respiração celular a partir do uso da ferramenta mencionada e a análise dos mesmos, caracterizou os seus aspectos quantitativos e qualitativos. Alunos e professores da rede pública da região metropolitana de Fortaleza/Ce, constituíram o grupo amostral. Os resultados obtidos demonstraram que a ferramenta testada, poderá auxiliar professores e alunos no ensino e na aprendizagem da respiração celular.
\end{abstract}

Palavras-chave: Ensino; Aprendizagem; Ferramenta.

\begin{abstract}
Information and Communication Technologies - ICTs, bring new possibilities for teaching and learning topics specific to Biochemistry. Hybrid teaching and active methodologies, associated with educational technological tools, can determine the breaking of paradigms in the scope of pedagogical practice. To analyze the relationship between hybrid teaching and the active inverted classroom methodology, this work used the Bio Respiration application, a teaching tool to facilitate the teaching of cellular respiration. The use of specific questionnaires on the teaching of cellular respiration from the use of the mentioned tool and the analysis of them, characterized its quantitative and qualitative aspects. Students and teachers from the public network of the metropolitan region of Fortaleza / Ce, constituted the sample group. The results obtained demonstrated that the tested tool can assist teachers and students in teaching and learning cellular respiration.
\end{abstract}

Keywords: Teaching; Learning; Tool.

\section{Resumen}

Las Tecnologías de la Información y la Comunicación - TIC, traen nuevas posibilidades para la enseñanza y el aprendizaje de temas propios de la Bioquímica. La enseñanza mixta y las metodologías activas, asociadas a herramientas tecnológicas educativas, pueden determinar la ruptura de paradigmas en el contexto de la práctica pedagógica. Para analizar las relaciones entre el blended learning y la metodología activa en el aula invertida, este trabajo utilizó la aplicación Bio Respiração, una herramienta didáctica para facilitar la enseñanza de la respiración celular. La utilización de cuestionarios específicos sobre la enseñanza de la respiración celular a partir del uso de la mencionada herramienta y su análisis, caracterizó sus aspectos cuantitativos y cualitativos. Estudiantes y profesores de escuelas públicas de la región metropolitana de Fortaleza/Ce constituyeron el grupo de la muestra. Los resultados obtenidos demostraron que la herramienta probada puede ayudar a profesores y estudiantes en la enseñanza y aprendizaje de la respiración celular.

Palabras clave: Enseñando; Aprendiendo; Herramienta. 


\section{Introdução}

Segundo os Parâmetros Curriculares Nacionais para o Ensino Médio -PCNEM (2000), a Biologia tem como objetos de estudo, todas as manifestações que caracterizam e buscam descrever o fenômeno vida. Neste contexto, entender o funcionamento das células por meio de seus processos vitais e compreender o que as caracterizam como unidade morfofuncional da vida, é essencial para que os alunos compreendam as relações existentes entre os níveis macroscópicos e microscópicos abordados pela Biologia.

A utilização de estratégias facilitadoras como as ferramentas tecnológicas, podem ser promissoras na superação de abstrações próprias dos conteúdos biológicos a serem ensinados e aprendidos, contribuem para ultrapassar as barreiras de uma educação bancária e, portanto, tradicional. A educação tradicional é caracterizada pela figura do professor que detém o conhecimento e do aluno que é o "depósito" do conhecimento de quem ensina (Freire, 2015). O aluno é um agente passivo no processo de ensino e aprendizagem, e o professor é o transferidor de conhecimentos e valores, sendo esta educação conhecida como "bancária".

Dentre diversas ferramentas pedagógicas, as disponibilizadas pelas TICs podem auxiliar nos processos de ensino e aprendizagem, já que ampliam as possibilidades de construção da autonomia e, portanto, do protagonismo dos estudantes, sendo o professor, fundamental na mediação do processo educativo, por meio da inserção das novas tecnologias (Rodrigues, 2021). As posturas e os comportamentos dos docentes como facilitadores poderão motivar os aprendizes para comandar as tecnologias, cooperando para que os mesmos sejam sujeitos ativos de sua própria aprendizagem (Moran et al., 2000).

Bacich e Moran (2018), afirmam que a aprendizagem é ativa quando é propositiva, ou seja, quando a escola, o professor e os sistemas de ensino, conseguem planejar ações que provoquem nos alunos, um avanço nos níveis de aprendizagens, onde os conhecimentos mais simples, são bases para os conhecimentos cada vez mais complexos, dando significados e trazendo, consequentemente, reflexões para aqueles que aprendem.

As Orientações Educacionais Complementares aos Parâmetros Curriculares Nacionais para o Ensino Médio - PCN+ (2000) corroboram com as afirmações realizadas acerca da importância na escolha das metodologias de ensino em Biologia. Neste sentido, é oportuno destacar que as inovações metodológicas diretamente ligadas às TICs, podem trazer contribuições significativas para o trabalho docente, permitindo deduzir que novas possibilidades e oportunidade de interações com o mundo moderno, poderão promover mediações entre os conteúdos, os alunos e os professores, superando as relações entre os que ensinam e os que aprendem. A cultura digital e a cultura escolar se entrelaçam, pois, discentes, docentes, pais e demais pessoas envolvidas no processo de ensino e aprendizagem, pertencem a um universo onde a tecnologia está presente (Bacich, Neto \& Trevisani, 2015).

A inclusão de metodologias de ensino inovadoras que se utilizam de modelos didáticos tridimensionais, vídeos e demais recursos disponíveis, facilitam o ensino de forma dinâmica, uma vez que a aprendizagem de conteúdos abstratos, os avanços nos métodos e recursos utilizados, poderão amenizar possíveis dificuldades encontradas. Ensinar Biologia requer do professor habilidades específicas, considerando que a Ciência em questão, traz uma linguagem própria, com uma variedade de conceitos que são necessários para o entendimento dos muitos processos e mecanismos que buscam explicar o fenômeno da vida (Duré et al., 2018).

Os desafios que se apresentam para o professor em sua atuação e formação docente diante dos conteúdos presentes nos currículos, notadamente no tocante a Biologia no ensino médio, podem ser superados por meio das novas metodologias de ensino, sendo o ensino híbrido, uma oportunidade para incluir o uso das novas tecnologias disponíveis.

O ensino híbrido, é aquele em que se mistura, se integra, se complementam com as várias possibilidades de tempos, de espaços, de metodologias variadas e de recursos diversos, visando uma gama de possibilidades que possam determinar e atender as novas demandas de um novo público que podem aprender de diversas formas (Bacich et al., 2015). O ensino híbrido 
abre novos caminhos a serem trilhados pelos professores e alunos. As TICs se apresentam como um novo campo de possibilidades e perspectivas para a criação de novos modelos e de metodologias por meio de aplicativos que venha auxiliar na interatividade necessária entre o professor e o aluno e destes, com o conhecimento científico (Bervian et al., 2016).

Há necessidade de integrar os recursos didáticos aos demais elementos que em conjunto, determinam um cenário propício para uma aprendizagem significativa (Farias, et al., 2014). Considerando a realidade digital, os recursos próprios desta realidade, o uso destes, podem potencializar à ação e às práticas docentes.

O diferencial nas propostas próprias ou que definem as metodologias ativas, se concentra nos aspectos ligados às posturas ou nos comportamentos dos alunos (Dias \& Valpato, 2017). Os mesmos autores afirmam que os recursos tecnológicos, são fundamentais para a interação entre os conhecimentos, o fazer pedagógico do professor e a aprendizagem dos alunos. O mundo digital está interligado ao mundo real (Moran, 2015). Dessa forma, o professor precisa estar atendo as tecnologias digitais, incluindo-as em sala de aula e instigando a sua utilização, para que o aluno possa continuar aprendendo em outros espaços e tempos de convívio social aos quais os mesmos estão inseridos.

A pesquisa apresentada, foi realizada a partir da utilização do aplicativo Bio Respiração, considerando os preceitos das metodologias ativas no contexto das TICs. A referida ferramenta, traz em sua configuração, links de acesso as diversas informações que têm como objetivo, detalhar as etapas da respiração celular, no escopo do ensino de Bioquímica. São elencadas definições importantes acerca de estruturas e processos que caracterizam a respiração aeróbica, assim como, são mostradas imagens e animações de estruturas que participam dos referidos processos bioquímicos celulares, responsáveis pela produção de energia para os seres vivos aeróbicos.

Ao longo da exploração dos elementos que constituem o aplicativo, é possível ampliar as imagens disponibilizadas através de toques sobre as mesmas, assim como, voltar para o menu inicial e rever conceitos importantes para melhor assimilar as informações necessárias para a compreensão do tema abordado de modo dinâmico e com autonomia para aprender.

$\mathrm{O}$ aplicativo dispõe ainda, de um conjunto de testes que podem ser utilizados como avaliação da aprendizagem dos alunos. Os testes foram disponibilizados ao final de cada uma das três etapas que compõe a respiração aeróbica. A decisão de disponibilizar um teste ao final de cada etapa do processo de respiração, se deu baseada na necessidade do aluno fazer uma revisão do que estudou, onde aluno poderá, assim como, nos testes disponibilizados nas etapas presentes no aplicativo, verificar o que acertou, podendo retornar e melhorar o seu desempenho diante dos mesmos.

Buscando estabelecer uma contextualização dos conteúdos abordados com o ensino de Biologia, especificamente, os conteúdos relacionados a respiração celular, o aplicativo Bio Respiração traz uma aba contendo uma sugestão de sequência didática a partir de temas que podem ser trabalhados de modo investigativo. Os temas denominados de "Hora da investigação", poderão trazer novas possibilidades para o aprofundamento do estudo e da importância da aprendizagem e do ensino da Bioquímica como uma área fundamental da Biologia.

Os temas propostos para investigação como por exemplo, mitocôndrias e o câncer, os radicais livres, mitocôndrias e a termogênese, as mitocôndrias e o envelhecimento, podem ser de suma importância para aproximar os conhecimentos da bioquímica com outros conteúdos e áreas da Biologia. A referida ferramenta está disponível no Play Store no endereço https://play.google.com/store/apps/details?id=com.biorespiracao e na Apple Store, podendo ser baixada a partir da pesquisa com as palavras Bio Respiração.

O referido trabalho de pesquisa teve como objetivos: a) pautar a discussão sobre o uso de aplicativo como instrumento auxiliar para professores e alunos no ensino da bioquímica da respiração celular; b) analisar a importância do uso das TICs junto aos professores de Biologia; c) favorecer o debate sobre a construção e uso de materiais didáticos tecnológicos junto aos professores de Biologia do ensino médio da rede pública; d) analisar o uso de aplicativo referente às etapas da respiração celular com os alunos e professores, com vistas a verificar a aprendizagem dos mesmos a partir da referida ferramenta de 
ensino; d) incentivar o protagonismo na construção de materiais didáticos por alunos e professores da rede pública de ensino que corrobore com novas práticas e meios para adquirir conhecimentos dentro da realidade das TICs.

\section{Metodologia}

A pesquisa foi realizada a partir das premissas do método quanti-qualitativo. O referido método leva em consideração o delineamento de questões ou problemas que podem adotar de forma específica, diversos assuntos por meio de questionários e entrevistas, oportunizando análises sobre os mesmos (Dalfovo et al., 2008).

Para a realização da pesquisa com alunos, inicialmente foi realizada aula expositiva dialogada com os mesmos, onde foi disponibilizado um questionário sobre a abordagem do conteúdo respiração celular. No final deste primeiro momento, foi disponibilizado o link do aplicativo Bio Respiração para que os alunos pudessem baixar e estudar o referido conteúdo abordado no intuito de favorecer o protagonismo estudantil para aprender em outros tempos e espaços e em seguida apresentar tais conhecimentos e os aspectos que caracterizam a metodologia ativa sala de aula invertida.

Em um segundo momento, os discentes responderam a um segundo questionário, objetivando a busca por respostas sobre a eficácia do aplicativo disponibilizado no primeiro momento da referida pesquisa. A Quadro 1, mostra as perguntas do questionário respondido pelos alunos.

Quadro 1. Questionário estruturado para os discentes após a aula expositiva dialogada (questões 01 e 02) e após a utilização do aplicativo Bio Respiração (questões 03, 04, 05 e 06).

\begin{tabular}{|c|c|}
\hline PERGUNTA & ALTERNATIVAS \\
\hline $\begin{array}{l}\text { 01. Você tem dificuldades de aprender os conteúdos próprios da } \\
\text { respiração celular e suas etapas? }\end{array}$ & $\begin{array}{l}\text { ( ) Sim. } \\
\text { ( ) Não. }\end{array}$ \\
\hline $\begin{array}{l}\text { 02. Em sua opinião, qual ou quais fatores, comprometem a } \\
\text { aprendizagem da bioquímica da respiração celular? }\end{array}$ & $\begin{array}{l}\text { a) A aprendizagem dos alunos depende exclusivamente do interesse } \\
\text { de cada um. } \\
\text { b) A aula expositiva dialogada é suficiente para que o aluno } \\
\text { compreenda as etapas da respiração celular. } \\
\text { c) A falta de instrumentos que auxilie o professor no ensino das } \\
\text { etapas da respiração celular compromete a aprendizagem dos } \\
\text { alunos. } \\
\text { d) Independentemente dos recursos oferecidos pelo professor, a } \\
\text { origem social do aluno está relacionada à aprendizagem e interesse } \\
\text { por conteúdos escolares como as etapas da respiração celular. }\end{array}$ \\
\hline $\begin{array}{l}\text { 03. Em sua opinião, um aplicativo para celular contendo as } \\
\text { etapas bioquímicas da respiração celular, favorece a } \\
\text { compreensão e o ensino e a aprendizagem do referido conteúdo } \\
\text { no ensino médio? }\end{array}$ & $\begin{array}{l}\text { ( ) Sim. } \\
\text { ( ) Não. }\end{array}$ \\
\hline $\begin{array}{l}\text { 04. Você acha que os aplicativos educacionais poderão facilitar } \\
\text { a aprendizagem dos conteúdos escolares? }\end{array}$ & $\begin{array}{l}\text { ( ) Sim. } \\
\text { ( ) Não. }\end{array}$ \\
\hline $\begin{array}{l}\text { 05. Qual a sua avaliação do aplicativo utilizado nos encontros } \\
\text { realizados? }\end{array}$ & $\begin{array}{l}\text { a) Desnecessário, pois os conteúdos sobre a respiração celular } \\
\text { podem ser aprendidos satisfatoriamente por meio de aulas } \\
\text { expositivas dialogadas. } \\
\text { b) Necessário, pois o conteúdo sobre a respiração celular pode ser } \\
\text { melhor aprendido por meio de aplicativo. }\end{array}$ \\
\hline $\begin{array}{l}\text { 06. O aplicativo lhe ajudou na compreensão dos conteúdos } \\
\text { propostos? }\end{array}$ & $\begin{array}{l}\text { ( ) Sim. } \\
\text { ( ) Não. }\end{array}$ \\
\hline
\end{tabular}

Fonte: Elaborada pelos autores.

O momento de realização da pesquisa com os professores seguiu uma sequência de duas etapas, em que foram disponibilizados dois questionários. Assim como foi realizado com os alunos, o primeiro questionário continha perguntas sobre o ensino da respiração por meio de aulas expositivas dialogadas. Nesta etapa da pesquisa, foi disponibilizado o link do 
aplicativo para que os professores analisem o mesmo, e em um segundo momento, os docentes respondessem a um segundo questionário, que pretendeu buscar informação sobre a utilização do aplicativo Bio Respiração e sua função para a obtenção de resultados que viessem auxiliar o ensino e a aprendizagem nas aulas sobre respiração celular. O Quadro 2 contém o questionário disponibilizado para os professores.

Quadro 2. Questionário estruturado para os docentes antes do acesso ao aplicativo Bio respiração (questões 01, 02 e 03) e após a utilização do aplicativo Bio Respiração (questões 04 e 05).

\begin{tabular}{|c|c|}
\hline PERGUNTA & ALTERNATIVAS \\
\hline $\begin{array}{l}\text { 01. Você tem dificuldades de ministrar aulas sobre a respiração } \\
\text { celular e suas etapas? }\end{array}$ & $\begin{array}{l}\text { ( ) Sim. } \\
\text { ( ) Não. }\end{array}$ \\
\hline $\begin{array}{l}\text { 02. Em sua opinião, um aplicativo poderia amenizar as } \\
\text { dificuldades no processo de ensino e aprendizagem das etapas } \\
\text { da respiração celular? }\end{array}$ & $\begin{array}{l}\text { ( ) Sim. } \\
\text { ( ) Não. }\end{array}$ \\
\hline $\begin{array}{l}\text { 03. Você gostaria de ter um aplicativo para celular com as } \\
\text { abordagens das etapas da respiração celular? }\end{array}$ & $\begin{array}{l}\text { ( ) Sim. } \\
\text { ( ) Não é necessário. }\end{array}$ \\
\hline $\begin{array}{l}\text { 04. Em sua opinião, um aplicativo para celular contendo as } \\
\text { etapas bioquímicas da respiração celular, poderá favorecer a } \\
\text { compreensão e o ensino e a aprendizagem do referido conteúdo } \\
\text { no ensino médio? }\end{array}$ & $\begin{array}{l}\text { ( ) Sim. } \\
\text { ( ) Não. }\end{array}$ \\
\hline $\begin{array}{l}\text { 05. Em sua opinião, qual ou quais fatores, comprometem o } \\
\text { ensino e aprendizagem da bioquímica da respiração celular? }\end{array}$ & $\begin{array}{l}\text { a) A aprendizagem dos alunos depende exclusivamente do interesse } \\
\text { de cada um. } \\
\text { b) A aula expositiva dialogada é suficiente para que o aluno } \\
\text { compreenda as etapas da respiração celular. } \\
\text { c) A falta de instrumentos que auxilie o professor no ensino das } \\
\text { etapas da respiração celular compromete a aprendizagem dos } \\
\text { alunos. } \\
\text { d) Independentemente dos recursos oferecidos pelo professor, a } \\
\text { origem social do aluno está relacionada a aprendizagem e interesse } \\
\text { por conteúdos escolares como as etapas da respiração celular. }\end{array}$ \\
\hline
\end{tabular}

Fonte: Elaborada pelos autores.

O projeto de pesquisa apresentado foi aprovado pelo Comitê de Ética em pesquisa - CEP, da universidade a qual a pesquisa foi submetida sob o número do Parecer: 3.302.472 e CAAE: 11935019.4.0000.5294. A construção do aplicativo, denominado Bio Respiração, foi idealizado para facilitar a compreensão de questões relacionadas ao tema Respiração celular, com destaque para a respiração aeróbica no ensino médio. O aplicativo Bio Respiração, foi protocolado sob o número BR 5120210001265 e registrado no Instituto Nacional da Propriedade Industrial - INPI.

\section{Resultados e Discussão}

\subsection{Dados da pesquisa com alunos}

Os dados foram obtidos a partir das respostas de vinte e cinco estudantes do primeiro ano do ensino médio de uma escola pública localizada na região metropolitana de Fortaleza-Ce que responderam às perguntas dos questionários disponibilizados. a figura 1 corresponde a pergunta 01: você tem dificuldades de aprender os conteúdos próprios da respiração celular e suas etapas? A maioria dos alunos, $76 \%$ do total, afirmaram não ter dificuldades em aprender os conteúdos próprios da respiração aeróbica, sendo que os $24 \%$ restantes, afirmaram ter dificuldades em aprender o referido conteúdo. 
Figura 1. Identificação com o conteúdo respiração celular.

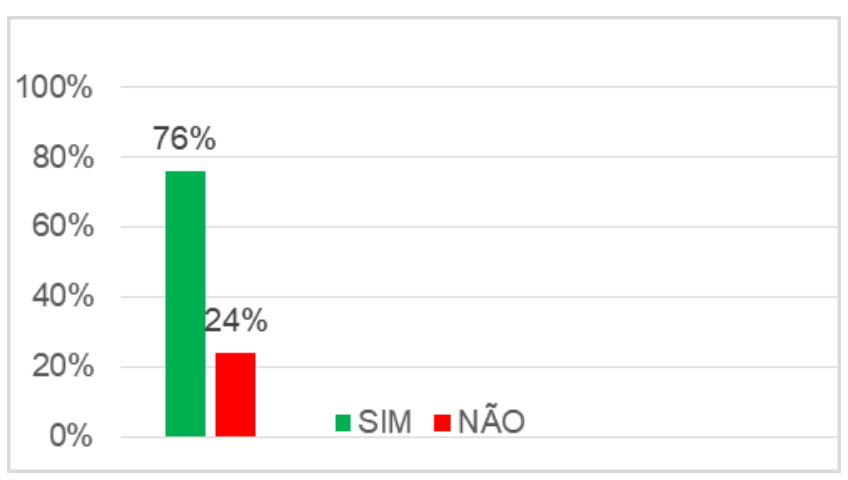

Fonte: Elaborada pelos autores.

A inclusão de ferramentas ou recursos tecnológicos de apoio ao ensino de conteúdos da Bioquímica contribui para a compreensão de conceitos e, consequentemente, corroboram para a efetivação do processo de ensino e de aprendizagem (Alcântara \& Filho, 2015).

A Figura 2, se refere a pergunta 02. Em sua opinião, qual ou quais fatores, comprometem a aprendizagem da bioquímica da respiração celular? Possíveis respostas para a questão levantada: a) A aprendizagem dos alunos depende exclusivamente do interesse de cada um;

b) A aula expositiva dialogada é suficiente para que o aluno compreenda as etapas da respiração celular; c) A falta de instrumentos que auxiliem o professor no ensino das etapas da respiração celular compromete a aprendizagem dos alunos elou; d) Independentemente dos recursos oferecidos pelo professor, à origem social do aluno está relacionada à aprendizagem e interesse por conteúdos escolares como as etapas da respiração celular.

De acordo com os dados obtidos na Figura 2,72\% dos alunos afirmaram que a aprendizagem depende exclusivamente do interesse de cada um, o que pode ser considerado contraditório, quando se analisa os dados da primeira pergunta. Nenhum aluno concordou que a aula expositiva dialogada, a qual eles estiveram presentes no primeiro momento da pesquisa, seja uma metodologia suficiente para a aprendizagem do conteúdo curricular, respiração celular.

O fato mencionado pode ser reafirmado, quando $68 \%$ dos alunos participantes da pesquisa manifestaram que a falta de instrumentos ou ferramentas que possam auxiliar o professor e os alunos no ensino e na aprendizagem da respiração aeróbica, poderá dificultar o ensino do respectivo assunto. A educação deve apresentar estratégias para acompanhar a modernidade e conectividade do mundo atual, transformando-o e determinando o progresso necessário ao desenvolvimento das sociedades (Dias \& Valpato, 2017). 
Figura 2. Fatores que podem comprometer a aprendizagem o ensino da respiração celular.

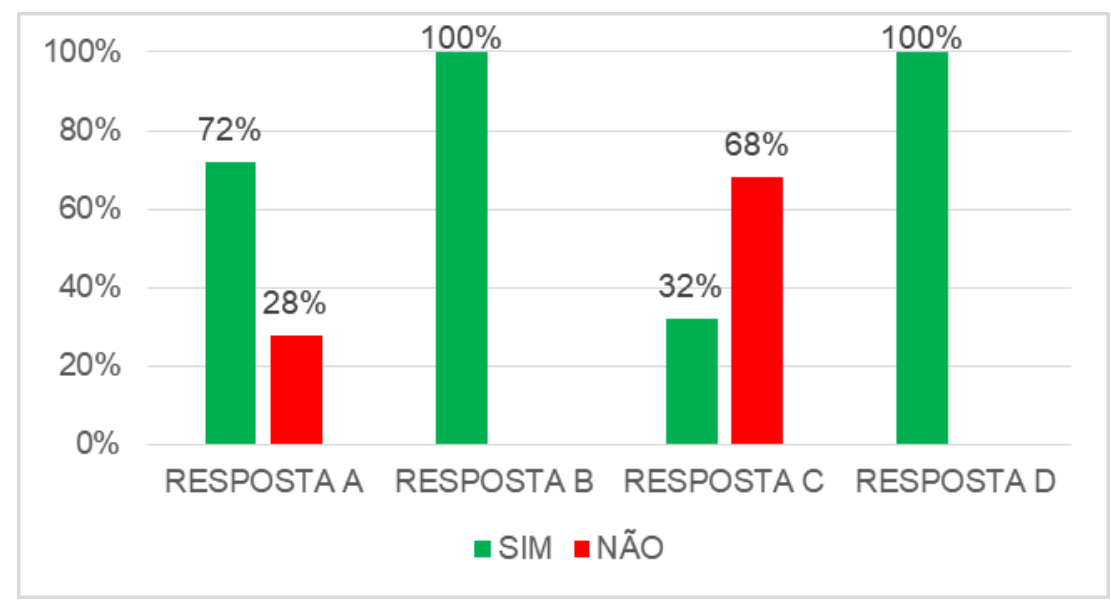

Fonte: Elaborada pelos autores.

Foi unânime entre os alunos pesquisados (100\%), que a origem social das pessoas que estão na escola, é determinante para a aprendizagem dos conteúdos escolares. Existe uma diversidade de sujeitos que chegam até o espaço escolar, marcados pelo ocultamento histórico e que exigem o reconhecimento de suas vivências e realidades (Arroyo, 2013). Os dados aferidos neste item da pesquisa, traz, portanto, discussões sobre elementos de cunho social e econômico, que não podem deixar de ser considerados no processo de ensino e aprendizagem.

Já a Figura 3, representa os resultados obtidos a partir das perguntas: 03. Em sua opinião, um aplicativo para celular contendo as etapas bioquímicas da respiração celular, favorece a compreensão e o ensino e a aprendizagem do referido conteúdo no ensino médio? 04. Você acha que os aplicativos educacionais poderão facilitar a aprendizagem dos conteúdos escolares? 05. Qual a sua avaliação do aplicativo utilizado nos encontros realizados? 06. O aplicativo lhe ajudou na compreensão dos conteúdos propostos?

Figura 3. Percepção dos alunos diante da utilização do aplicativo Bio Respiração.

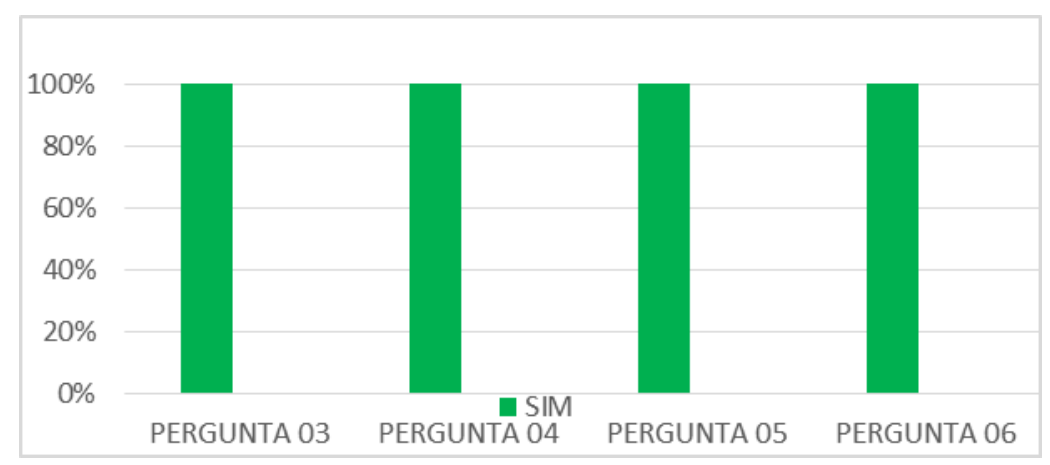

Fonte: Elaborada pelos autores.

A introdução do aplicativo na segunda aula da pesquisa, teve como objetivo, experimentar a metodologia ativa, sala de aula invertida, associada ao uso da ferramenta Bio Respiração. As metodologias ativas podem ser consideradas como técnicas ou estratégias que foram criadas para atender as necessidades próprias do mundo digital (Dias \& Valpato, 2017). A sala de aula invertida se constitui numa forma do professor particularizar ou personificar o ensino para cada um de seus alunos, já que é dada uma liberdade para aprender em outros tempos e espaços (Bergmann \& Sams, 2018).

Os dados obtidos mostraram que todos os alunos participantes da pesquisa, concordaram que o uso de recurso tecnológico Bio Respiração, favorece a compreensão dos conteúdos próprios da respiração celular, pois, facilita o ensino e a 
aprendizagem do referido conteúdo. Quando a aprendizagem é focada no aluno, este, atuará de forma ativa, tendo o docente o papel fundamental no planejamento de suas atividades, se posicionando como mediador do processo de ensino e aprendizagem (Silva et al., 2017).

Os recursos e as técnicas de ensino precisam ser escolhidos considerando o que é pretendido para que os alunos aprendam. Desta forma, o uso das novas tecnologias como instrumentos ou meios, poderá contribuir para o ensino e aprendizagem (Moran et al., 2000). As Tecnologias da Informação e Comunicação - TICs facilitam processos de interações com a realidade, uma vez que as mesmas apresentam várias possibilidades nas formas de mostrar fenômenos de modo versátil (Dias \& Valpato, 2017).

Franco (2021), esclarece que o aparelho celular é uma ferramenta que dispões de uma gama de possibilidades, sendo uma delas, passível de ser utilizada como ferramenta educativa, por ser dinâmica nas suas funções, além de ser popular entre as diversas pessoas e no convívio social. Neste sentido, aplicativos para aparelhos celulares que possuem conteúdos educativos, considerando a evolução destes mesmos aparelhos, possibilitam novas formas de acesso à conhecimentos que outrora, somente poderiam estar presentes em livros didáticos e demais materiais impressos ou mesmo em computadores e na internet. A mediação do ensino por meio de ferramentas tecnológicas pode determinar aprendizagem mais sólidas, pois, possibilitam novas formas de interações dos alunos nos processos de construção de novos conhecimentos (Carneiro et al., 2020).

\subsection{Dados da pesquisa com professores}

Os dados foram obtidos a partir das respostas de onze professores de escolas públicas da região metropolitana de Fortaleza-Ce, que responderam as perguntas dos questionários disponibilizados. De acordo com os dados apresentados na Figura 4, do total de onze professores participantes da pesquisa, 91\% afirmaram ter dificuldades em ministrar aulas sobre a respiração celular, sendo que do total, um docente, ou $9 \%$ do todo, afirmou não ter dificuldades em ministrar aulas sobre o respectivo conteúdo. Os dados foram obtidos a partir da pergunta 01: Você tem dificuldades de ministrar aulas sobre a respiração celular e suas etapas?

Figura 4. Identificação ou aptidão dos professores acerca do ensino da bioquímica da respiração celular.

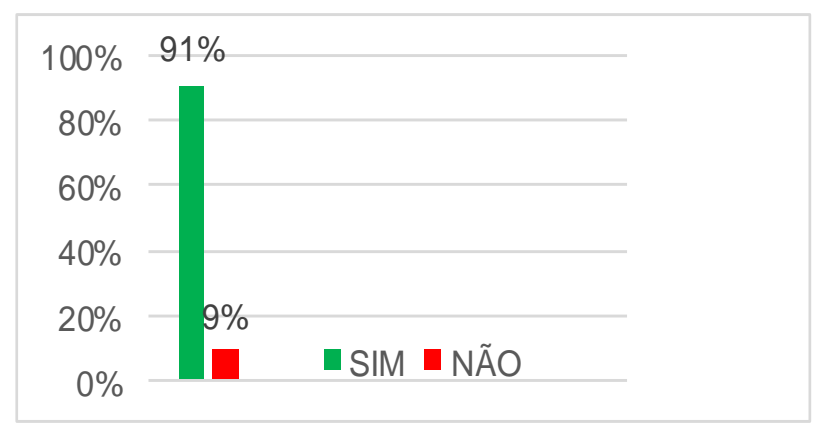

Fonte: Elaborada pelos autores.

Apesar da necessidade do aprendizado de conceitos básicos, o ensino restrito ao livro didático, poderá comprometer o ensino dos conteúdos de Bioquímica (Dias, et., 2013). O aplicativo Bio Respiração, possui GIFs, figuras que podem ser ampliadas e em ainda figuras no formato 3D, favorecendo a compreensão da respiração celular e, assim, trazer novas possibilidades de uma maior interação entre os alunos e o conteúdo abordado.

A Figura 5, traz informações relevantes sobre a utilização de recursos tecnológicos no ensino de processos celulares como a respiração aeróbica. Os dados da referida figura, confirmaram as possíveis dificuldades em ministrar o tema presente 
no aplicativo a partir das perguntas: 02. Em sua opinião, um aplicativo poderia amenizar as dificuldades no processo de ensino e aprendizagem das etapas da respiração celular? 03.Você gostaria de ter um aplicativo para celular com as abordagens das etapas da respiração celular? 04. Em sua opinião, um aplicativo para celular contendo as etapas bioquímicas da respiração celular, poderá favorecer a compreensão e o ensino e a aprendizagem do referido conteúdo no ensino médio?

Figura 5. Verificação da eficácia do aplicativo Bio Respiração frente aos objetivos de incluir ferramentas digitais no ensino de assuntos próprios da biologia, como é o caso da respiração celular.

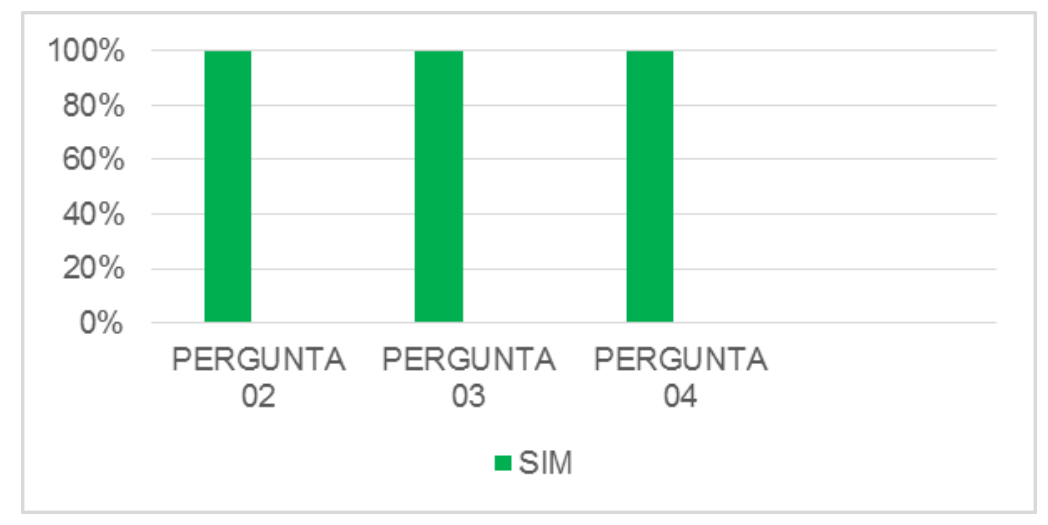

Fonte: Elaborada pelos autores.

Todos os professores participantes da pesquisa (100\%) concordaram que a utilização de um recurso tecnológico como o aplicativo analisado, poderá facilitar o ensino e a aprendizagem da respiração celular. As metodologias ativas, são fundamentais para que a autonomia e protagonismos daqueles que aprendem, sejam efetivadas (Mazuin \& Gomes, 2019). Os autores esclarecem, que na atualidade, é cada vez mais exigido, uma formação profissional pautada em competências e habilidades voltadas e conectadas com a realidade vivenciada pelas gerações atuais. Dessa forma, as ferramentas de ensino e de aprendizagem podem ser inseridas nas metodologias ativas, no sentido de atender as novas demandas do ensino e da aprendizagem no contexto atual.

Considerando as transformações ocorridas no mundo e, consequentemente, nos paradigmas que envolvem a educação que está atrelada às mudanças sociais, econômicas e culturais, existe uma necessidade vigente, de uma reorganização nas estruturas de sustentação dos sistemas de ensino, estando à formação docente no centro desta discussão (Veiga \& Amaral, 2012). No contexto da modernidade tecnológica é competência dos professores, utilizar os recursos tecnológicos disponíveis, a fim de aproximar os conteúdos à realidade tecnológica com vistas a diversificar as propostas de ensino e de aprendizagem das escolas (Perrenoud, 2000). As respostas dos professores, portanto, colaboram com os anseios por uma educação que esteja atenta à realidade dos recursos e ferramentas tecnológicas disponíveis e que não devem estar de posse apenas de grupos específicos da sociedade.

Considerando o debate sobre a escolha do currículo do ensino médio e a Biologia, que poderá se configurar em uma área do conhecimento em que os seus conteúdos, dependendo da sua abordagem, poderá afastar ou provocar curiosidades nos discentes (Nascimento, 2015). Desta forma, a diversificação de metodologias associadas a utilização de ferramentas tecnológicas de aprendizagem, como o aplicativo Bio Respiração, poderá contribuir para o ensino de conteúdos como a bioquímica da respiração celular de modo a atender as necessidades de inovação nos processos de ensino e de aprendizagem.

Para a obtenção dos resultados apresentados na figura 6, foi realizada a pergunta 05 , com as seguintes possíveis respostas, respectivamente: Em sua opinião, qual ou quais fatores, comprometem o ensino e aprendizagem da bioquímica da respiração celular? a) A aprendizagem dos alunos depende exclusivamente do interesse de cada um; b) A aula expositiva dialogada é suficiente para que o aluno compreenda as etapas da respiração celular; 
c) A falta de instrumentos que auxilie o professor no ensino das etapas da respiração celular compromete a aprendizagem dos alunos e lou; d) Independentemente dos recursos oferecidos pelo professor, a origem social do aluno está relacionada a aprendizagem e interesse por conteúdos escolares como as etapas da respiração celular.

Figura 6. Fatores que comprometem o ensino e aprendizagem na visão dos professores.

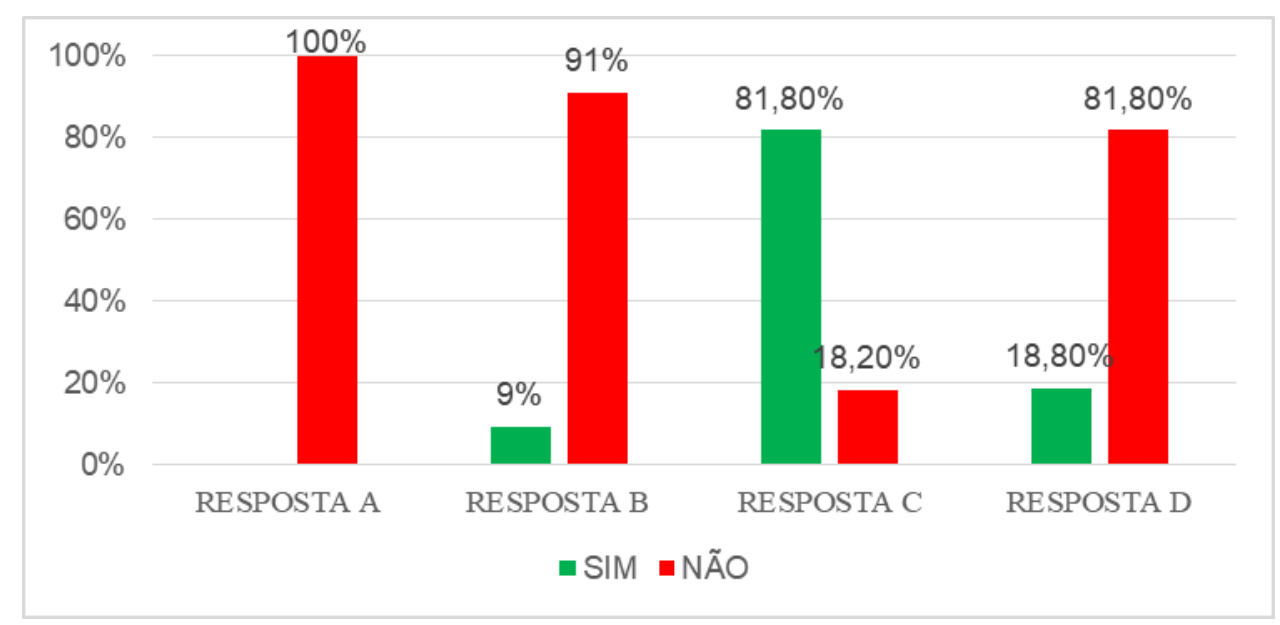

Fonte: Elaborada pelos autores.

Todos os professores participantes da pesquisa (100\%) concordaram que a aprendizagem, não depende única e exclusivamente do esforço do aluno, alternativa A. Um docente, que corresponde a $9 \%$ do total, concordou que a aula expositiva dialogada é suficiente para que os alunos compreendam a respiração celular, alternativa B. Em relação a utilização de instrumentos disponíveis, no caso, o aplicativo Bio respiração para o ensino da respiração celular, 81,80\% dos docentes, concordaram que tal recurso pode auxiliar na compreensão do tema em discussão alternativa C. Para um ensino em que haja uma interatividade entre alunos, professores e conteúdo, é essencial o uso de ferramentas para este fim (Cardoso, et al., 2004).

A Figura 6, mostra que 18,20\% dos participantes, afirmaram que o contexto social ao qual o aluno está inserido, tem relações com o seu interesse em assuntos científicos abstratos, como a respiração celular. Muitos são os fatores que permeiam e que podem interferir na atuação do professor de Biologia, entre eles, a desmotivação e indisciplina dos discentes, as condições de trabalho, a desvalorização docente e a escassez de recursos (Nascimento, et al., 2015).

Os dados obtidos e apresentados na figura 6 podem ampliar as discussões, acerca do planejamento das ações pedagógicas, a partir das várias realidades dos alunos que chegam até a escola. O planejamento didático deverá estar pautado na realidade, sendo que os recursos ou materiais de trabalho contribuem para alcançar os objetivos educacionais (Farias, et. al., 2014). Dessa forma, considerando o ensino da Bioquímica da respiração com a utilização, da ferramenta Bio Respiração, traz contribuições relevantes para o tema abordado.

\section{Conclusões}

Os resultados obtidos a partir da pesquisa realizada com discentes e docentes mostraram que o uso do aplicativo Bio Respiração se mostrou como uma ferramenta importante no ensino da respiração celular, considerando que o mesmo, pode ser integrado como recurso didático às metodologias de ensino que surgiram nos últimos anos, notadamente, as metodologias ativas como é o caso da sala de aula invertida. A pesquisa de campo realizada, demonstrou que as discussões acerca da temática sobre as novas formas de atuação dos sistemas de ensino, das escolas e dos docentes, não estão encerradas porque, mesmo diante do aparato tecnológico e as novas demandas sociais vinculadas com a evolução digital, a existência de práticas tradicionais ainda é comum e precisa ser superada. 
Neste sentido, a pesquisa traz possibilidades de inovações futuras no ensino e na aprendizagem, visando despertar nos estudantes, professores e demais interessados, novas pesquisas no âmbito das novas tecnologias que podem e devem estar relacionadas com a educação, de forma a atender as novas demandas por um ensino e uma aprendizagem conectada com a modernidade vivenciada.

\section{Agradecimentos}

À Coordenação de Aperfeiçoamento de Pessoal de Nível Superior - Brasil (CAPES), pelo apoio e financiamento do Programa de Mestrado Profissional em Ensino de Biologia - PROFBIO. À Universidade do Estado Rio Grande do Norte UERN pelo apoio Institucional e ao Colegiado do PROFBIO pelas contribuições.

\section{Referências}

Alcântara, N. R.; Filho, A. V. M. (2015). Elaboração e utilização de um aplicativo como ferramenta no ensino da Bioquímica. Revista de Ensino de Bioquímica. Revista de Ensino de Bioquímica; 13(3) https://redib.org/Record/oai_articulo913018-elabora\%C3\%A7\%C3\%A3o-e-utiliza\%C3\%A7\%C3\%A3ode-um-aplicativo-como-ferramenta-ensino-de-bioqu\%C3\%ADmica-carboidratos-lip\%C3\%ADdios-prote\%C3\%ADnas-e-\%C3\%A1cidos-nucleicos

Arroyo, Miguel, G. (2013). Currículo, território em disputa. (5a ed.), Vozes.

Bergmann, J., \& Sams, A. (2018). Sala de aula invertida: uma metodologia ativa de aprendizagem. LTC.

Brasil. Ministério da Educação. (2000). Parâmetros Curriculares Nacionais para o Ensino Médio. Ciências da Natureza, Matemática e suas Tecnologias. http://portal.mec.gov.br/seb/arquivos/pdf/ciencian.pdf

Brasil. Ministério da Educação. (2000). Orientações Educacionais Complementares aos Parâmetros Curriculares Nacionais - PCN+. Ciências da Natureza, Matemática e suas Tecnologias. http://portal.mec.gov.br/seb/arquivos/pdf/CienciasNatureza.pdf

Bervian, P. V., Marin, J. C., \& Dutra, P. (2016). As Tecnologias da Informação e Comunicação no Ensino de Ciências e Biologia a partir da análise dos anais do Enpec. Revista da SBEnBio. Número 9. VI Enebio e VIII Erebio Regional 3. http://www.sbenbio.org.br/wordpress/wp-content/uploads/renbio9/pdfs/1982.pdf

Bacich, L.\& Moran, J. (2018). Metodologias ativas para uma educação inovadora: uma abordagem teórico-prática. Penso.

Bacich, L., Neto, A. T, \& Trevisani, F. M. (2015). Ensino híbrido: personalização e tecnologia na educação. Penso.

Cardoso, V. A., Ricardo, J., Figueiredo, L. F., Merino, E.; Antonio, R.V., Sugai, J. K., Figueiredo, M. S. R. B., \& Heidrich, D. N. (2004). “Carboidratos na natureza": construção de software educacional para cursos de extensão. Revista Extensivo. Florianópolis, Ano 1 Edição - $\mathrm{N}^{\circ}$ : 01. https://periodicos.ufsc.br/index.php/extensio/article/view/1421

Carneiro, L. A., Rodrigues, W., F., \& Prata, D. N. (2020). Uso de tecnologias no ensino superior público brasileiro em tempos de pandemia COVID-19. Research, Society and Development, 9(8), e267985485. http://dx.doi.org/10.33448/rsd-v9i8.5485.

Dalfovo, M. S., Lana, R. A., \& Silveira, A. (2008) Métodos quantitativos e qualitativos: um resgate teórico. Revista Interdisciplinar Científica Aplicada, 2(4), 01-13, http://rica.unibes.com.br/index.php/rica/article/view/243/234

Dias, S, R., \& Valpato, A. N. (Org.). (2017) Práticas inovadoras em metodologias ativas. Contexto Digital.

Dias, G., Oliveira, F. S., Pascutti, P. G., \& Biancone, N. L. (2013). Desenvolvimento de ferramentas multimidiáticas para o ensino de bioquímica. - Revista Práxis. 5(9). http://revistas.unifoa.edu.br/index.php/praxis/article/view/599/550.

Duré, R. C., Andrade, M. J. D., \& Abílio, F. J. P. (2018). Ensino de biologia e contextualização do conteúdo: quais temas o aluno de ensino médio relaciona com o seu cotidiano? Teaching biology and contextualization of content: which subjects the High School student realize in your daily life? Experiências em Ensino de Ciências 13(1). http://if.ufmt.br/eenci/artigos/Artigo_ID471/v13_n1_a2018.pdf

Farias, I. M. S., Sales, J. O. C. B., Braga, M. M. S. C., \& França, M. S. L. M. (2014). Didática e docência: aprendendo a profissão. (4a ed.) Liber Livro.

Franco, R. M. (2021). O uso do smartphone como recurso pedagógico no ensino de biologia: uma sequência didática proposta. http://143.106.227.105/bitstream/REPOSIP/364761/1/Franco_RhaisaMartins_M.pdf

Freire, P. (2013). Pedagogia do oprimido. (54a ed.), Paz e Terra.

Mazuim, C. H. R., \& Gomes, M. S. S. (2019) Teorias e Vivências de Metodologias ativas. Perse.

Moran, J. M., Masetto, M. T., \& Behrens, M. A. (2000). Novas tecnologias e mediação pedagógica. Papirus.

Moran, J. M. (2015). Mudando a educação com metodologias ativas. [Coleção Mídias Contemporâneas. Convergências Midiáticas, Educação e Cidadania: aproximações jovens. Vol. II] Carlos Alberto de Souza e Ofelia Elisa Torres Morales (orgs.). PG: Foca Foto-PROEX/UEPG. http://www2.eca.usp.br/moran/wp-content/uploads/2013/12/mudando_moran.pdf 
Research, Society and Development, v. 11, n. 3, e21611326373, 2022

(CC BY 4.0) | ISSN 2525-3409 | DOI: http://dx.doi.org/10.33448/rsd-v11i3.26373

Nascimento, M. S. B., Silva, C. H. S., Fernades, E. F., Dantas, F. K. S., \& Sobreira, A.C.M. (2015). Desafios à prática docente em biologia: o que dizem os professores do ensino médio? EDUCERE XII Congresso Nacional De Educação PUCPR. http://educere.bruc.com.br/arquivo/pdf2015/18007_10120.pdf

Perrenoud, P. (2000). Dez novas competências para ensinar. Artmed.

Rodrigues, E. T. (2021). Tecnologias de Informação e Comunicação (TIC) no ensino de ciências e biologia : a produção acadêmica nos Cursos de Ciências Biológicas da UFPB / Eranio Túlio Rodrigues. - João Pessoa, 2021. 61 p. https://repositorio.ufpb.br/jspui/bitstream/123456789/21718/1/ETR23122021.pdf

Silva, A. R. L., Bieging, P., \& Busarello, R. I. (2017) Metodologia ativa na educação. Pimenta Cultural.

Veiga, I. P. A., \& Amaral, A. L. (orgs.). (2012) Formação de professores: Políticas e debates. (5a ed.), Papirus. 